\title{
O uso do Teodolito no estudo das Relações Trigonométricas no Triângulo Retângulo
}

\author{
Activity using theodolite involving the relationships of the rectangle \\ triangle
}

\begin{abstract}
Andreia Belter (uni.deiabelter@gmail.com)
Acadêmica do $5^{\circ}$ semestre, Curso de Licenciatura em Matemática do Instituto Federal Farroupilha (IFFar - Campus Santa Rosa), Grupo de Pesquisa: Modelagem matemática e Educação Matemática
\end{abstract}

Júlia Gabriela Petrazzini da Silva (juliagpetrazzini@gmail.com) Acadêmica do $5^{\circ}$ semestre, Curso de Licenciatura em Matemática do Instituto Federal Farroupilha (IFFar - Campus Santa Rosa), Grupo de Pesquisa: Modelagem matemática e Educação Matemática

Kelly Gabriela Poersch (kellygabrielapoersch@gmail.com) Acadêmica do $5^{\circ}$ semestre, Curso de Licenciatura em Matemática do Instituto Federal Farroupilha (IFFar - Campus Santa Rosa), Grupo de Pesquisa: Modelagem matemática e Educação Matemática

Julhane Alice Thomas Schulz (julhane.schulz@iffarroupilha.edu.br) Doutora em Modelagem Computacional - Docente do Instituto Federal Farroupilha (IFFar Campus Santa Rosa), Grupo de Pesquisa: Modelagem matemática e Educação Matemática

Elizangela Weber (elizangela.weber@iffarroupilha.edu.br) Mestre em Modelagem Matemática - Docente do Instituto Federal Farroupilha (IFFar - Campus Santa Rosa), Grupo de Pesquisa: Modelagem matemática e Educação Matemática

Resumo: O presente relato discorre acerca de uma prática pedagógica desenvolvida pelas bolsistas de um projeto de pesquisa vinculado ao curso de Licenciatura em Matemática do Instituto Federal Farroupilha (IFFar) - Campus Santa Rosa. A prática foi desenvolvida com estudantes do $2^{\circ}$ ano do Curso Técnico Integrado, da mesma Instituição. Com o intuito de simplificar a compreensão da Trigonometria no Ensino Médio, são de grande valia as atividades, que envolvem situações reais e possibilitam compreender a aplicação de conceitos abstratos. No desenvolvimento desta prática de ensino, utilizou-se um Teodolito rudimentar para coletar informações, que foram tratadas matematicamente por meio de relações trigonométricas no triângulo retângulo. Esta proposta didática teve como objetivo descobrir alturas de alguns prédios do IFFar que a princípio seriam inatingíveis, porém, tendo conhecimento de algumas medidas e ângulos pode-se usar as relações trigonométricas do triângulo retângulo para solucionar o problema em questão. A proposta do uso do Teodolito no ensino da Trigonometria foi eficaz perante os objetivos traçados, uma vez que os alunos mostraram-se motivados e envolvidos com a atividade, em que o professor passou a ser somente o orientador da aprendizagem e os alunos os protagonistas desenvolvendo a autonomia na resolução de problemas matemáticos.

Palavras-chave: Atividade Prática; Investigação Matemática; Trigonometria.

Recebido em: $14 / 08 / 2020$

Aceito em: $1 \% / 12 / 2020$ 
Abstract: The present report discusses a pedagogical practice developed by the fellows of a research project linked to the Mathematics Degree course at the Federal Farroupilha Institute (IFFar) - Campus Santa Rosa. The practice was developed with students of the 2nd year of the Integrated Technical Course, from the same Institution. In order to simplify the understanding of Trigonometry in High School, activities that involve real situations and make it possible to understand the application of abstract concepts are of great value. In the development of this teaching practice, students used a rudimentary theodolite to collect information, which was treated mathematically through trigonometric relations in the right triangle. The objective of this didactic proposal was to discover heights of some IFFar buildings that at first would be unattainable, however, having knowledge of some measures and angles, the trigonometric relations of the right triangle can be used to solve the problem in question. The proposal to use theodolite in the teaching of Trigonometry was effective in view of the objectives set, since the students were motivated and involved with the activity, in which the teacher became only the learning advisor and the students the protagonists developing autonomy in solving mathematical problems.

Keywords: Mathematical Investigation; Practical activity; Trigonometry.

Resumen: Este informe analiza una práctica pedagógica desarrollada por los becarios de un proyecto de investigación vinculado al curso de Matemáticas en el Instituto Federal Farroupilha (IFFar) - Campus Santa Rosa. La práctica se desarrolló con alumnos del $2^{\circ}$ año del Curso Técnico Integrado, de la misma institución. Para simplificar la comprensión de la trigonometría en la escuela secundaria, las actividades que involucran situaciones reales y permiten comprender la aplicación de conceptos abstractos son de gran valor. En el desarrollo de esta práctica docente, los estudiantes utilizaron un teodolito rudimentario para recopilar información, que fue tratada matemáticamente a través de relaciones trigonométricas en el triángulo rectángulo. El propósito de esta propuesta didáctica era descubrir las alturas de algunos edificios de IFFar que al principio serían inalcanzables, sin embargo, al tener conocimiento de algunas medidas y ángulos, las relaciones trigonométricas del triángulo rectángulo pueden usarse para resolver el problema en cuestión. La propuesta de usar teodolito en la enseñanza de la trigonometría fue efectiva en vista de los objetivos establecidos, ya que los estudiantes estaban motivados e involucrados en la actividad, en la cual el maestro se convirtió en solo un asesor de aprendizaje y los estudiantes protagonistas que desarrollaron autonomía en resolviendo problemas matemáticos.

Palabras-clave: Actividad Práctica; Investigación Matemática; Trigonometría.

\section{INTRODUÇÃO}

Este estudo teve como proposta o ensino de Trigonometria no Triângulo Retângulo, vinculado ao uso do teodolito, com duração de 2 períodos de 50 minutos cada, em uma turma de $2^{\circ}$ ano do Curso Técnico Integrado do Instituto Federal Farroupilha, campus Santa Rosa.

Recebido em: $14 / 08 / 2020$

Aceito em: $1 \% / 12 / 2020$ 
A sequência didática utilizada nesta prática faz parte da proposta do projeto de pesquisa intitulado "Educação Matemática pelo viés de materiais manipulativos e tecnológicos: elaboração de propostas didáticas para a Educação Básica”. A idealização deste projeto tem por fundamento a contribuição de maneira ativa para a melhoria na qualidade de ensino da Matemática, estabelecendo um contato direto entre o Curso de Licenciatura em Matemática e a Educação Básica, permitindo uma aproximação com a prática escolar nesta modalidade de ensino, considerando que o curso de Licenciatura em Matemática tem por objetivo a formação de professores que atuarão neste nível de ensino.

São inúmeras as dificuldades encontradas no processo de ensino e aprendizagem da Matemática, as quais, muitas vezes, são desencadeadas pelo desgosto à disciplina. Por isso, é necessário que o professor faça uso de recursos e metodologias que facilitem a aprendizagem, a fim de instigar o interesse dos alunos pela mesma. Conforme Santi, Santos e Webler (2009, p.3):

Assim como as metodologias de ensino, o uso de material concreto em sala de aula é potencial, sendo que auxilia o educando no processo de aprendizagem e proporciona a este visualizar o que se está trabalhando, ele adquire um melhor entendimento da linguagem abstrata que está sendo explorada.

O uso do teodolito rudimentar foi escolhido por ser de fácil construção e baixo custo, além de conseguir atender o objetivo proposto para a atividade: calcular a altura de prédios através da distância entre o sujeito e o edifício, empregando o ângulo encontrado com o uso do teodolito.

No decorrer deste relato, encontra-se a fundamentação teórica, a metodologia utilizada, a descrição da atividade e as análises, resultados e discussões realizadas.

\section{EMBASAMENTO TEÓRICO DAS RELAÇÕES TRIGONOMÉTRICAS E DO TEODOLITO}

Ao pensar em um planejamento, a escolha da metodologia leva em consideração vários aspectos, como os objetivos da aula, a proposta didática estruturada, o conteúdo abordado, as características da turma e os recursos disponíveis. Então, ao optar pela Investigação Matemática, como metodologia, na prática relacionada às relações trigonométricas e ao uso do teodolito, torna-se evidente o desenvolvimento do Recebido em: 14/08/2020 
raciocínio lógico e da autonomia, a demonstração da utilidade dos conceitos matemáticos no cotidiano, o desejo de instigar os alunos a participar ativamente da aula e a busca por materiais alternativos no ensino da Matemática.

\subsection{Investigação Matemática}

$\mathrm{O}$ ato de investigar representa a ação de examinar, ou descobrir algo novo, podese considerar muito útil na aprendizagem da Matemática, pois o aluno poderá fazer descobertas, elaborar questões e discuti-las juntamente com o professor e os colegas. Além disso, Lorenzon (2019, p.2) afirma que "a investigação é entendida como uma prática que, por permitir a formulação de hipóteses, a exploração, a manipulação de materiais e a interação com os pares e com o meio favorece a aprendizagem das crianças".

Na Investigação Matemática o professor assume o papel de mediador e facilitador, no processo de ensino e aprendizagem, enquanto o aluno é convidado a fazer o papel de investigador matemático, permitindo que ele estabeleça questões e os possíveis caminhos para chegar à solução, possibilitando a ele que construa seu próprio conhecimento. De acordo com a Base Nacional Comum Curricular (BNCC):

Para que esses propósitos se concretizem nessa área, os estudantes devem desenvolver habilidades relativas aos processos de investigação, de construção de modelos e de resolução de problemas. Para tanto, eles devem mobilizar seu modo próprio de raciocinar, representar, argumentar, comunicar e, com base em discussões e validações conjuntas, aprender conceitos e desenvolver representações e procedimentos cada vez mais sofisticados. (BRASIL, 2018, p.519)

Ou seja, a Investigação Matemática possibilita, nos alunos, a autonomia, o desenvolvimento de habilidades de compreensão e a visão da Matemática não somente como um conjunto de regras e técnicas, mas também o habilita a:

(...) agir como um matemático, não só na formulação de questões e conjecturas e na realização de provas e refutações, mas também na apresentação de resultados e na discussão e argumentação com os seus colegas e o professor. (PONTE, BROCARDO, OLIVEIRA,2019, p.23)

\subsection{O uso do Material Concreto}

O trabalho em sala de aula com o auxílio de materiais concretos influencia diretamente na aprendizagem e assimilação dos conteúdos, além de influenciar em outros aspectos, como, propiciar aulas mais dinâmicas e interativas, incentivar a 
investigação e a pesquisa, mas também, o interesse e a curiosidade dos alunos, para que eles estabeleçam relações entre as situações experienciadas na manipulação de tais materiais e os conceitos trabalhados em sala de aula, a fim de dar sentido ao conhecimento abstrato dos conceitos estudados. Porém, "requer do professor não apenas o conhecimento específico dos conceitos trabalhados, mas o uso de metodologias de ensino e atividades diferenciadas mais eficientes" (WEBER; ABITANTE; FUCHS; MAROSTEGA, 2018, p.2).

Contudo, para que isso ocorra, é de fundamental importância que o professor tenha clareza e domínio do conteúdo e também, conheça os alcances e possibilidades de extrapolação que este material concreto pode vir a desencadear, preparando-se para, administrar possíveis contratempos em sua proposta.

Além disso, é indispensável que o professor atue como mediador da prática, pois, segundo Novello et al. (2009, p.5):

Utilizar o material concreto por si só, não garante aprendizagem, é fundamental o papel do professor nesse processo, enquanto mediador da ação e articulador das situações experienciadas no material concreto e os conceitos matemáticos, para uma posterior abstração e sistematização.

Neste sentido, o material concreto não é o único recurso para a compreensão da Matemática, porém, pode ser muito eficiente, mas para isso, deve ser utilizado e analisado de forma crítica, para que se avalie sua efetividade em relação à aprendizagem dos alunos.

\subsection{Relação do Triângulo Retângulo com o Teodolito}

A partir do triângulo retângulo fundamentam-se vários axiomas e teoremas, como algumas relações trigonométricas, que auxiliam arquitetos e engenheiros na construção dos mais diversos projetos arquitetônicos, mediante sua incorporação, do que se chama atualmente, de teodolito. Tendo como base a Figura 1, pode-se analisar as seguintes relações fundamentais utilizadas no teodolito rudimentar.

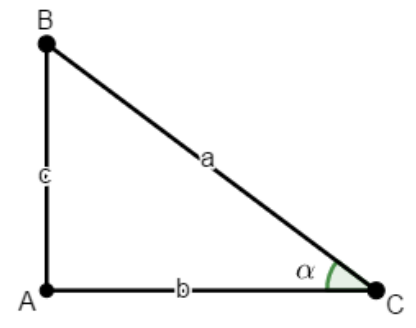

Recebido em: $14 / 08 / 2020$

Aceito em: $1 \% / 12 / 2020$ 
Figura 1 - Relações trigonométricas do triângulo retângulo.

Observando a Figura 1 visualiza-se que: este triângulo retângulo possui dois catetos, $\underline{A C}$ e $\underline{A B}$ que correspondem, respectivamente, ao segmento de reta denominado "b" e "c", e a hipotenusa, $\underline{B C}$, é denominada "a". Além disso, ao considerar-se o ângulo alfa, $\alpha$, como ponto de observação, infere-se as concepções de que: o lado "b" é o cateto adjacente à $\alpha$, o lado "c" é o cateto oposto à $\alpha$, e "a" continua como hipotenusa do triângulo. Com estas concepções e conhecimentos básicos de Trigonometria formam-se, as seguintes, proposições (1):

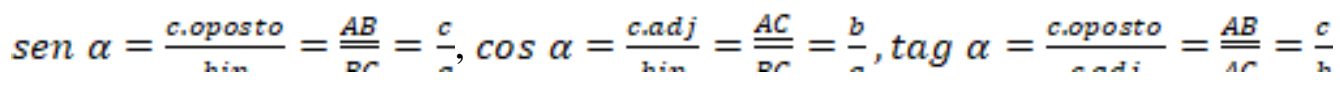

Apoiado nestas conjecturas é possível, estimar, com o teodolito rudimentar, a altura de prédios, de maneira simples e rápida, atendendo a estas etapas: primeiro, devese ter um teodolito; segundo, precisa-se saber a qual distância, do prédio, se está e se ela forma um ângulo reto com o prédio; terceiro, a partir da utilização do teodolito sabe-se o ângulo formado pela linha reta "imaginária" e o topo do prédio, que na Figura 1 chamou-se $\alpha$; quarto, verificar a altura da pessoa, do chão à altura dos seus olhos, que irá olhar pelo teodolito; quinto, calcular a tangente do ângulo $\alpha$; e sexto, somar à altura da pessoa no quinto passo com a altura obtida no quarto passo.

Conhecendo esses dados precisa-se desvendar qual relação do triângulo retângulo deve-se escolher, uma vez que tem-se o ângulo, seu cateto adjacente e busca-se conhecer o cateto oposto. Logo, nota-se que a tangente é a fórmula adequada para este enunciado.

\subsection{Utilização do Teodolito}

Nesta prática fez-se o uso do Teodolito, que segundo Ferreira (2000, p.668) apud Almeida e Vieira (2013, p.5), é um "instrumento óptico para medir com precisão ângulos horizontais e verticais", usado também por arquitetos, engenheiros, topógrafos e antigos navegadores, a fim de determinar distâncias inacessíveis. Neste caso, a trena e o teodolito são os materiais que substituem a régua e o transferidor no papel.

Para utilizar o teodolito é necessário que se faça a medida da altura, do chão até a altura dos olhos, onde o teodolito é posicionado para medir o ângulo, do sujeito que utilizará a ferramenta. Após, o indivíduo ficará a uma distância do objeto que se quer 
calcular a altura, distância essa que deve ser devidamente medida e marcada. Em seguida, o sujeito irá manusear o teodolito a fim de, através do canudo, enxergar o topo do objeto, como por exemplo, um prédio. E enfim, se marcará o ângulo formado entre a posição do teodolito e o topo do local a ser medido.

Assim, sabendo a distância até o local e o ângulo formado, pode-se calcular a tangente do ângulo para descobrir a sua altura, como demonstra a Figura 2.

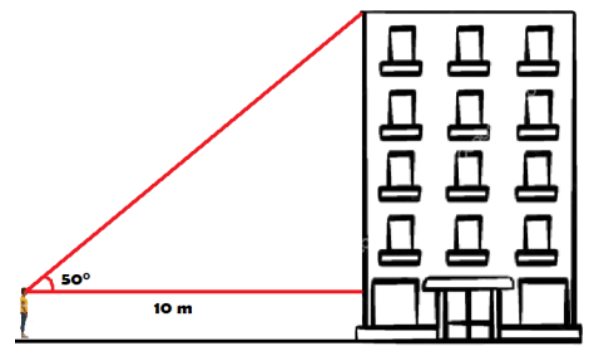

Figura 2 - Uso do teodolito para medir a altura do prédio.

Entretanto, precisa-se levar em conta a soma da medida descoberta através do cálculo da tangente com a medida que foi encontrada entre o chão e a altura da pessoa que fez a atividade, para assim, encontrar, neste caso, a altura do prédio.

\section{METODOLOGIA}

O estudo teve como proposta, o ensino da Trigonometria, com ênfase nas Relações Trigonométricas no Triângulo Retângulo, aliado ao uso do teodolito, com duração de 2 períodos de 50 minutos cada. Os sujeitos da pesquisa foram 53 estudantes do $2^{\circ}$ ano do Curso Técnico Integrado, do Instituto Federal Farroupilha (IFFar) Campus Santa Rosa.

Para a coleta de dados utilizou-se as atividades realizadas pelos alunos, e sua análise teve caráter qualitativo, em virtude dos três vieses considerados: a observação da prática, os dados e a teoria. Além disso, neste estudo buscou-se, atividades de cunho investigativo fundamentadas na metodologia de Investigação Matemática aliada a metodologia Expositiva e Dialogada e ao uso de material concreto. Visto que, segundo D’Ambrosio (1993, p.35) a Matemática é:

Uma disciplina em que o avanço se dá como consequência do processo de investigação e resolução de problemas. Além disso, é importante que o professor entenda que a Matemática estudada deve, de alguma forma, ser útil aos alunos, ajudando-os a compreender, explicar ou organizar sua realidade.

Recebido em: $14 / 08 / 2020$

Aceito em: $1 \% / 12 / 2020$ 
Para o desenvolvimento do planejamento em sala de aula, a metodologia principal utilizada foi a Investigação Matemática que segundo Ponte, Brocardo, Oliveira (2019), se dispõe em quatro momentos:

O primeiro abrange o reconhecimento da situação, a sua exploração preliminar e a formulação de questões. O segundo momento refere-se ao processo de formulação de conjecturas. O terceiro inclui a realização de testes e o eventual refinamento das conjecturas. E, finalmente, o último diz respeito à argumentação, à demonstração e a avaliação do trabalho realizado. (p.20)

Nesta conjectura, é imprescindível que o professor vincule a Matemática à realidade dos alunos, desassociando-a da concepção errônea de ser um conjunto de fórmulas sem sentido com exercícios mecânicos, das quais os alunos querem distância. Sendo assim, é visível o papel, fundamental, de práticas como esta, realizada em sala de aula cuja vivência proporcionada enriquece, imensuravelmente, os alunos, em vários âmbitos, não somente educacionais.

\section{DETALHAMENTO DAS ATIVIDADES}

Para a construção do Teodolito rudimentar, utilizado nesta prática, foram usados materiais simples como isopor, transferidor impresso em folha branca, canudo de plástico, fio e um chumbo de pesca, que serviu como pêndulo.

Primeiramente foram impressos 14 transferidores em folha branca A4, que foram recortados e colados em folhas de isopor. Após fazer o recorte da folha de isopor, devidamente demarcada pelo transferidor, foram colados os pêndulos no centro, onde marcou $90^{\circ}$, e os canudos, que serviram como ponto para observar o topo do objeto a ser calculado à altura, como demonstra a Figura 3.

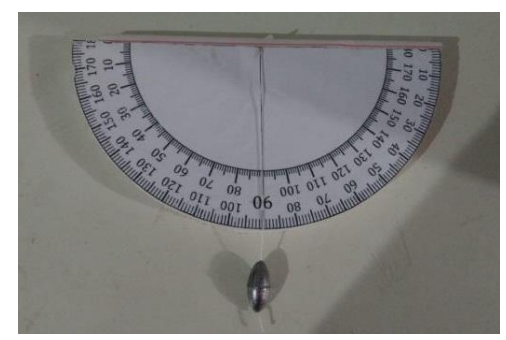

Figura 3 - Teodolito rudimentar.

Contemplando o primeiro passo da Investigação Matemática proposta por Ponte, Brocardo e Oliveira (2019), a professora fez uma breve revisão sobre triângulo 
retângulo, identificando seus lados e as relações trigonométricas já estudadas pela turma. Em seguida, os alunos foram organizados em grupos e foi proposta uma atividade investigativa. Utilizando uma maquete (Figura 4), a professora ilustrou um dos problemas que os alunos teriam de responder, muito próximo ao que aconteceria na atividade prática, o qual os alunos discutiram nos grupos, desenvolveram os cálculos pertinentes e em seguida responderam em suas folhas impressas.

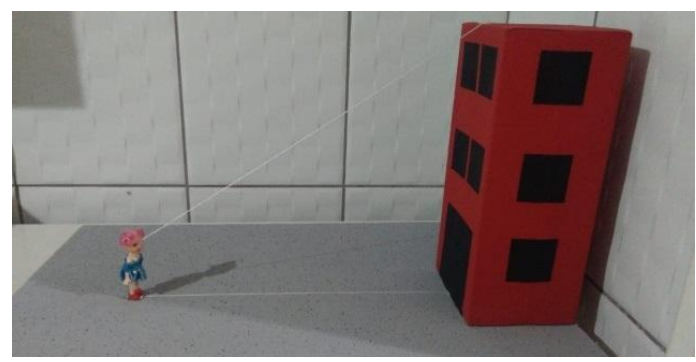

Figura 4 - Maquete representando a situação-problema.

Logo após, apresentou-se o teodolito construído pelas bolsistas, pois os alunos só conheciam como funcionava um Teodolito Profissional. Um integrante de cada grupo foi convidado para fazer uso do mesmo, a fim de calcular a altura do quadro, medindo este aluno até a altura dos olhos, onde o teodolito é posicionado para medir o ângulo. Em seguida, considerando a distância do aluno até o quadro, horizontalmente e por último, após conseguirem todos os dados, cada grupo pode calcular a altura do quadro da sala de aula (Figura 5), evidenciando assim o segundo passo da Investigação Matemática.

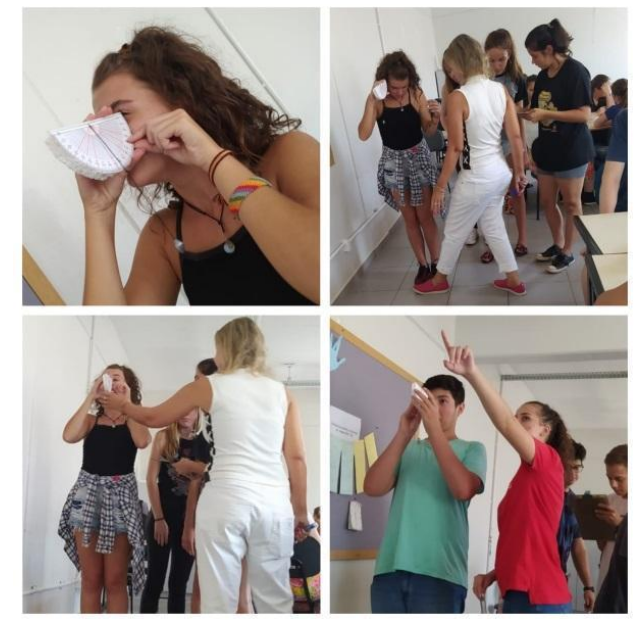

Figura 5 - Manuseio do Teodolito.

Para a internalização do terceiro passo da Investigação Matemática, que é a realização de testes e refinamento das conjecturas, propôs-se a realização da atividade 
prática, onde cada grupo foi encaminhado para locais diferentes do Campus, com intuito de medir a altura do Prédio Administrativo, da Biblioteca ou do Refeitório. Em cada um desses prédios as bolsistas auxiliaram os grupos para medir os ângulos formados entre a altura dos olhos do aluno e o topo de cada prédio. Para chegar a um valor mais próximo da altura real de cada prédio, solicitou-se que os alunos anotassem os ângulos formados por três distâncias diferentes, para depois fazer a média entre elas (Figura 6).
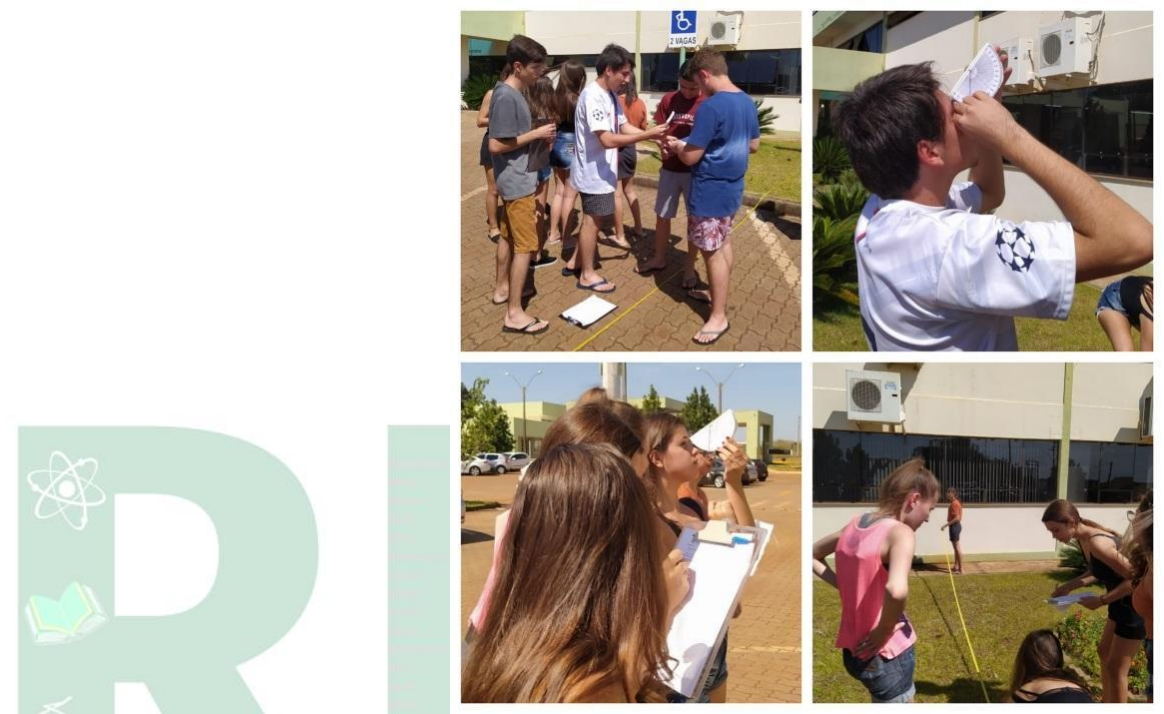

Figura 6 - Utilização do Teodolito para descobrir a altura dos prédios do Campus.

A fim de concluir o quarto passo da Investigação Matemática, sistematizando o trabalho realizado, os alunos retornaram para a sala de aula com as medidas necessárias, calcularam as alturas a partir das relações métricas do triângulo retângulo e ao concluir todos os cálculos, os grupos socializaram os resultados encontrados, evidenciando assim o poder da argumentação e avaliação dos alunos sob o trabalho proposto.

\section{RESULTADOS E DISCUSSÕES}

Refletindo sobre a prática, podemos observar que os alunos apresentaram domínio do conteúdo, assim como, empatia durante o trabalho em grupo, auxiliando um ao outro quando necessário e interagindo com questionamentos e proposições. Em um primeiro momento, na resolução da situação-problema ilustrada pela maquete, houve indagações e foi necessária uma breve retomada de conceitos, no entanto a maioria dos alunos apresentou domínio e entendimento sobre as relações trigonométricas no triângulo 
retângulo, e por consequência, desenvolveram a solução da situação-problema, com êxito.

Conforme a Figura 7 pode-se observar que os alunos souberam representar geométrica e algebricamente a interpretação do problema, bem como tinham ciência dos meios para apresentar a resolução esperada e relacionar a teoria da sala de aula e sua aplicação no problema, ou seja, souberam associar a teoria com a prática, trazendo significado ao estudo, pois de acordo com Pacheco, Barbosa e Fernandes (2017, p.337) "se a teoria e a prática forem realizadas de formas separadas ou isoladas não produzirão resultados significativos, partindo do pressuposto de que uma não é superior à outra".

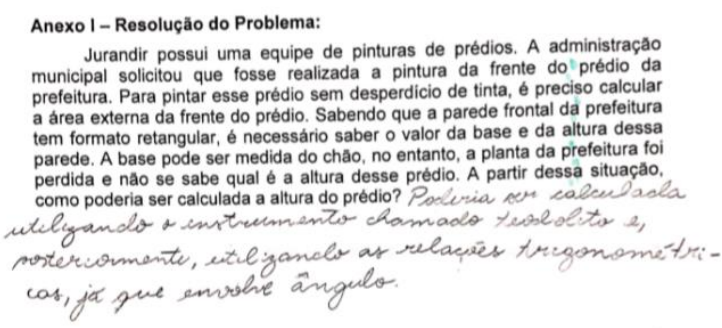

Fonte: Registro dos alunos, 2020.

Figura 7 - Resolução, do aluno, para a situação-problema.
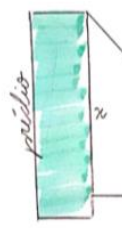

Jurandir, lembrou de suas aulas de Matemática, que utilizando a relaçâo da tangente em um triângulo retângulo é possivel calcular a altura de vários objetos, inclusive prédios. Sabendo que a distância entre o local em que sua auxiliar (cuja altura é de $1,63 \mathrm{~m}$ ) se posicionou para medir o angulo de estavam até o topo do prédio era de 60 graus, faça a representaçáo da situaçáo problema e determine a altura do prédio da Prefeitura.

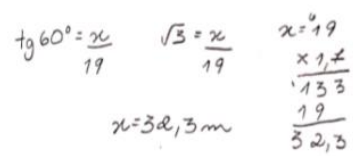

allura total $=32,3+1,63$ allura total $=33,93 \mathrm{~m}$

.


Anexo II - Medida do Quadro

i5g Altura do aluno que fará uso do teodolito até a altura dos olhos:

$158,3 \mathrm{~cm}$

- Distância do aluno ao quadro, horizontalmente: $300 \mathrm{~cm}$

medido: Ângulo formado entre a posiçâa do teodolito e o topo do local a ser

- Representação da situação-problema:

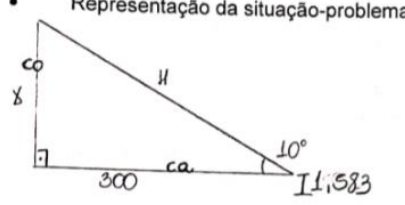

- Cálculo da altura do quadro da sala de aula:

$\operatorname{Tg} 10^{\circ}=\frac{c 0}{c a} \quad x=0,5 \quad 0,176$

$\frac{0,176}{1}=\frac{8}{3}$

$20, \frac{x 3}{528}$

$\frac{1,583}{2,111 \mathrm{~m}}$

Fonte: Registro dos alunos, 2020.

Figura 8 - Cálculo da altura do quadro.

Além disso, ressalta-se o entusiasmo, dos estudantes, durante o manuseio do Teodolito, observando e questionando quanto à forma de interpretar os ângulos obtidos, mas também, a maneira correta de posicionar-se para atingir o valor correto de inclinação, e com isso, evitar grandes discrepâncias no resultado final. Em vista disso, é notória a importância do uso de materiais manipuláveis em sala de aula, já que facilitam o entendimento em relação ao processo da atividade, bem como, propiciam a construção de estratégias para atender determinados desafios.

$\mathrm{Na}$ terceira etapa da atividade, que consistiu em realizar as medidas da altura de alguns prédios do campus, conforme discriminado em sala de aula, foi necessário verificar o local apropriado, ou seja, o mais plano horizontalmente possível; marcar três distâncias em uma única linha perpendicular em direção ao prédio, para garantir que o ângulo formado entre o observador e prédio seria de $90^{\circ}$, além da precisão ao verificar o ângulo formado. Uma vez que, a precisão destes dados implica na correta aplicação do cálculo da tangente, e consequentemente, o êxito do resultado final.

Na utilização do Teodolito, a fim de medir os ângulos formados entre o aluno observador e o prédio, cada grupo escolheu, aleatoriamente, as três distâncias para tal verificação, no entanto a partir de questionamentos das bolsistas e da própria experimentação, observaram que, quanto menor a distância que eles escolheram, mais difícil seria ver o topo do prédio e consequentemente verificar o ângulo, dado que ele seria maior.

Vale ressaltar a importância do uso de espaços não-formais como potencializadores da aprendizagem, visto que os mesmos podem despertar mais interesse e participação do aluno durante a aula, incentivar o pensamento crítico e ampliar a capacidade de resolver situações-problema, vindo ao encontro, desse modo, 
da proposta metodológica da Investigação Matemática. Ainda, conforme Jesus, Sena e Andrade (2014, p. 731) "os espaços informais contribuem significativamente para a construção de conhecimentos e formação profissional, potencializam o ensino formal e favorecem a ressignificação da experiência dos sujeitos".

Quanto aos resultados apresentados pelos grupos das alturas relativas a cada prédio do IFFar campus Santa Rosa, vale ressaltar que teve resultados próximos aos reais, e outros com grande diferença do resultado esperado (Figura 9). No entanto, o desenvolvimento matemático realizado pelos grupos, condiz com o conteúdo trabalhado em sala de aula, sendo assim cumprindo com o objetivo deste trabalho, aliar a teoria à prática da sala da aula.
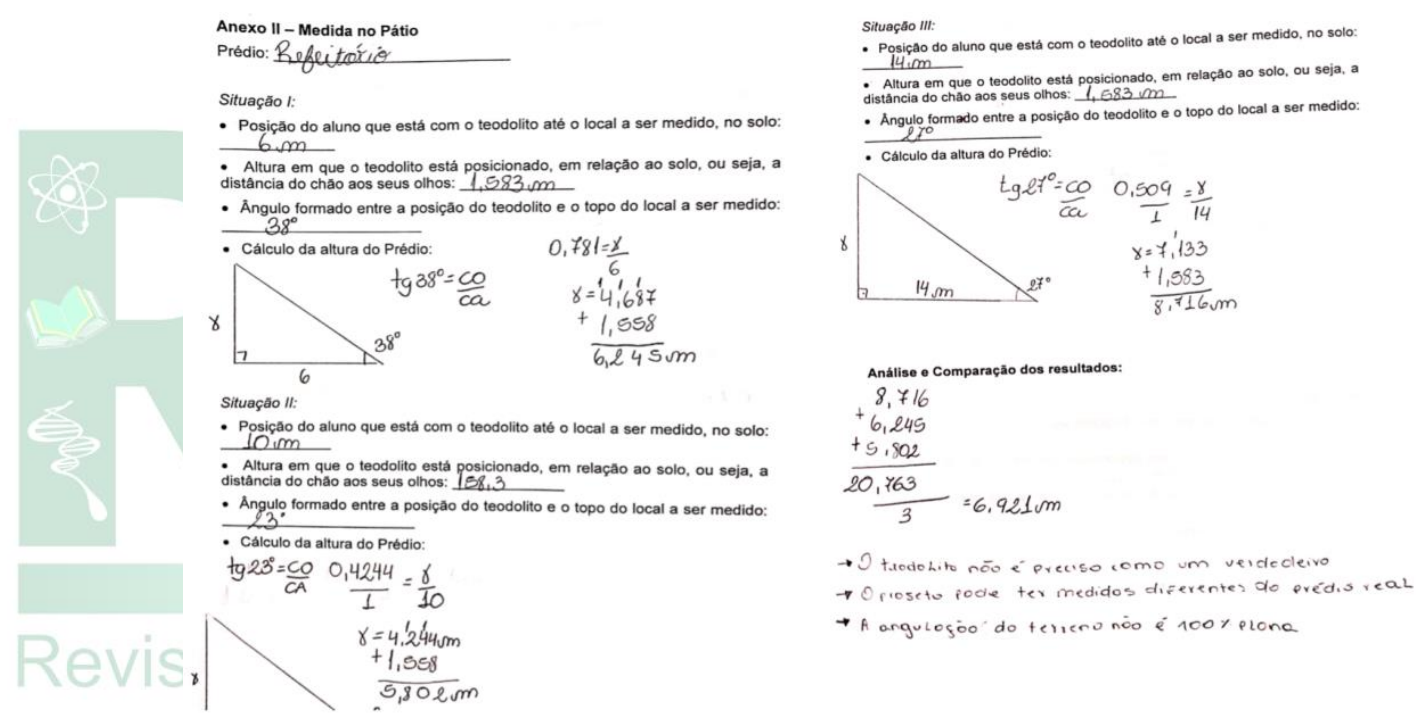

Fonte: Registro dos alunos, 2020.

Figura 9 - Resultados obtidos pelos alunos no prédio do refeitório.

Cabe salientar, que as discrepâncias encontradas nos resultados apresentados, podem ser justificadas pela utilização de materiais rústicos como o teodolito, que em vezes apresenta variações dos ângulos medidos, ou pelas irregularidades no solo fazendo com que a linha considerada não fosse perpendicular ao prédio a ser medido, ou ainda, pode-se considerar que as medidas, no projeto dos prédios contém diferenças em relação às medidas do prédio real, sem contar com a disposição do sol no momento das verificações dos ângulos, entre outras razões analisadas pelos alunos e discutidas nos grupos na socialização das atividades. 


\section{CONSIDERAÇÕES FINAIS}

A utilização de atividades práticas nas aulas de Matemática auxilia no processo de ensino e aprendizagem da mesma, vindo ao encontro da atividade de manusear o Teodolito e, a partir deste, relacioná-lo com os conceitos de relações trigonométricas no triângulo retângulo. Atividades como esta fazem com que os alunos percebam a aplicação dos conteúdos estudados em sala de aula, servindo, muitas vezes, de subsídio aos problemas encontrados na vida real, além de trazer conhecimento para futuros engenheiros, arquitetos, técnicos em edificações, topógrafos, agrimensores, entre outras áreas.

Para além disso, atividades que aliam a teoria com a prática são oportunidades para uma aprendizagem mais significativa, que estimulam a participação dos alunos, interação com colegas, trocas de experiências por meio das discussões de trabalho em grupo, desenvolvendo ainda mais a autonomia na resolução de problemas matemáticos. Pode-se salientar ainda, que, com a motivação demonstrada pelos alunos, o professor passou a ser somente o orientador e eles os protagonistas da aprendizagem.

Consequentemente, a chance de atuar, conjuntamente com a professora regente, e de experienciar o planejamento sendo desenvolvido em sala de aula, bem como, a reação dos alunos no desenvolver das atividades tornam-se eventos enriquecedores, tanto para a formação profissional, enquanto professoras em formação, quanto para constituição pessoal do ser. Pois, é possível, por intermédio dos fatos vivenciados, perceber quais são as falhas no planejamento, como também, as mudanças viáveis para o seu aprimoramento. Outrossim, os feedbacks instantâneos da turma estimulam a ânsia pela pesquisa e construções de novos materiais alternativos, com o intuito de promover a participação dos alunos, além da aprendizagem.

Por isto, deve-se ressaltar a importância da partilha de experiências, a qual pode ser feita através dos mais diversificados meios de comunicação, e, mesmo assim, fornecer informações relevantes, para outros docentes, sobre prática. Logo, com este subsídio, o docente consegue ter mais segurança acerca da atividade e visualizá-la de forma mais realista. Portanto, este Projeto de Pesquisa, mediante a prática relatada no decorrer do texto, possibilita o crescimento profissional, pessoal e intelectual, não somente dos indivíduos presentes no desenvolver da prática, mas também, para todos que tiverem conhecimento desta aula a partir da partilha de vivências.

Recebido em: $14 / 08 / 2020$

Aceito em: $1 \% / 12 / 2020$ 


\section{REFERÊNCIAS}

ALMEIDA, Dionara Freire de; VIEIRA, Andrea Cristina. Utilizando o teodolito no ensino da trigonometria. In: ENCONTRO NACIONAL DE EDUCAÇÃO

MATEMÁTICA, 11. 2013, Curitiba. Anais [...] Curitiba: Sociedade Brasileira de Educação Matemática - Regional Paraná, 2013. Disponível em:

<http://sbem.iuri0094.hospedagemdesites.ws/anais/XIENEM/pdf/132_208_ID.pdf>.

Acesso em: 24 mar 2020.

BRASIL. Base Nacional Comum Curricular: Educação é a Base - Ensino Médio.

Brasília: MEC, 2018. Disponível em:

http://basenacionalcomum.mec.gov.br/images/historico/BNCC_EnsinoMedio_embaixa site_110518.pdf. Acesso em: 08 ago. 2020.

D’AMBROSIO, Beatriz S. Formação de Professores de Matemática para o Século XXI: o grande desafio. Campinas: Cortez. Editora: UNICAMP, vol. 4 nº 1, 1993.

JESUS, Isabel Silva de; SENA, Edite Lago da Silva; ANDRADE, Luana Machado. Aprendizagem nos espaços informais e ressignificação da existência de graduandos de enfermagem. Revista Latino-Americana de Enfermagem. v.22, n.5, p731-738, setout, 2014. Disponível em: <https://www.scielo.br/pdf/rlae/v22n5/pt_0104-1169-rlae-2205-00731.pdf>. Acesso em: 09 ago 2020.

LORENZON, Mateus. Os Portfólios como instrumento avaliativo em uma proposta de Ensino por Investigação. Revista Insignare Scientia - RIS, v. 1, n. 3, 17 fev. 2019. Disponível em: <https://periodicos.uffs.edu.br/index.php/RIS/article/view/10595/7099> Acesso em: 15 jul. 2020.

NOVELLO, Tanise Paula; SILVEIRA, Daniel da Silva; LUZ, Vanessa Silva da; COPELLO, Gláucia Brasil; LAURINO, Débora Pereira. Material concreto: uma estratégia pedagógica para trabalhar conceitos matemáticos. Curitiba: PUCPR, 2009. Disponível em: <https://educere.bruc.com.br/arquivo/pdf2009/3186_1477.pdf> Acesso em: 01 jun. 2020.

PACHECO, Willyan Ramon de Souza; BARBOSA, João Paulo da Silva; FERNANDES, Dorgival Gonçalves. A Relação Teoria e Prática no Processo de Formação Docente. Revista de Pesquisa Interdisciplinar, Cajazeiras, n. 2, suplementar, p. 332- 340, set. de 2017.

PONTE, João Pedro da; BROCARDO, Joana; OLIVEIRA, Hélia. Investigações matemáticas na sala de aula. 4 ed. Belo Horizonte: Autêntica, 2019.

SANTI, Cassia Bordim; SANTOS, Rafael Marques dos; WEBLER, Geovane. Material Concreto na Compreensão dos Conceitos Matemáticos. In: COMPARTILHANDO SABERES, 1. 2017, Santa Maria. Anais [...]. Santa Maria: UFSM, 2017. Disponível em: http://coral.ufsm.br/compartilhandosaberes/wp-content/uploads/2018/12/CassiaBordim-Santi-MATERIAL-CONCRETO.pdf . Acesso em: 01 jun. 2020.

Recebido em: $14 / 08 / 2020$

Aceito em: $1 \% / 12 / 2020$ 
Vol. 3, n. 5. Set./Dez.

ISSN: 2595- 4520

WEBER, Elizangela; ABITANTE, Lucilaine Goin; FUCHS, Mariele Josiane;

MAROSTEGA, João Sidnei. Implementação do Laboratório de Ensino de Matemática em Escolas de Educação Básica: repensando o processo de ensino e aprendizagem. In: Revista Insignare Scientia - RIS, v. 1, n. 2, 24 ago. 2018. Disponível em:

<https://periodicos.uffs.edu.br/index.php/RIS/article/view/7797/5647>. Acesso em: 10 jul. 2020. 